\title{
Comparison of serum amyloid A protein and C-reactive protein concentrations in cancer and non-malignant disease
}

\author{
JG RAYNES, EH COOPER \\ From the Unit for Cancer Research, University of Leeds, Leeds LS2 9NL
}

SUMMARY Serum amyloid A (SAA) concentrations correlate well with C-reactive protein (CRP) concentrations. However, SAA is sometimes raised in disease when CRP is normal. This appears to occur more often in certain diseases such as rheumatoid arthritis, primary biliary cirrhosis and chronic active hepatitis. SAA concentrations did not distinguish between cancer with and without metastases as previously indicated, although mean concentrations were higher in more advanced tumours. Despite the higher sensitivity of SAA over CRP in the inflammatory response, SAA has little advantage over CRP in the assessment of malignant disease.

Serum amyloid $\mathbf{A}$ was first found in serum because it cross-reacted immunologically with antiserum raised against amyloid A protein purified from amyloid deposits. ${ }^{1-3}$ SAA has been shown to have a molecular weight of approximately 14000 daltons although in serum it was shown to have an effective molecular weight of 85000 to 200000 daltons depending on the conditions. ${ }^{1-4}$ This has been shown to be due to binding to high density lipoproteins (HDL), of which SAA is considered to be an apolipoprotein. ${ }^{56} \mathrm{SAA}$ is thought to be a precursor of amyloid fibrils ${ }^{2}$ and is synthesised in the liver.?

SAA has been demonstrated to be an acute phase reactant, its serum concentration increasing greatly in response to tissue damage or inflammation. ${ }^{89}$ SAA has been reported to be a biochemical marker that discriminates between disseminated and local or regional neoplastic disease. ${ }^{1011}$ SAA has also been reported to be raised in a variety of chronic inflammatory diseases such as rheumatoid arthritis and systemic lupus erythematosus, ${ }^{12}{ }^{13}$ inflammatory bowel disease, ${ }^{14}$ as well as in myelomatosis and benign monoclonal gammopathy. ${ }^{15}$ SAA has been observed to be moderately raised in pregnancy and old age ${ }^{16}$ although a more recent report has failed to confirm the increase in old age. ${ }^{17}$

C-reactive protein (CRP) is another better known acute phase reactant and serum concentrations of this protein have been shown to correlate with SAA. ${ }^{9}$ In this study concentrations of SAA and CRP were examined in blood samples from patients with a variety of diseases to see if SAA measurement was more informative than CRP especially in the assessment of malignant disease and its metastatic and local spread. The possible clearance of SAA by the kidney has also been examined.

\section{Patients and material and methods}

PATIENTS

Serum samples were obtained from blood donors (35 women and $35 \mathrm{men}$ ) and asymptomatic elderly men, aged 56-83 yr recalled 1-2 years after transurethral resection for benign prostatic hypertrophy (BPH) to observe any age-dependent effect on the normal concentrations. Serial samples were taken from seven patients undergoing elective cholecystectomy to observe the rate of change of SAA and CRP concentrations in response to wounding. Random $D$ samples were obtained from 86 patients with chronic liver disease, benign inflammatory gastrointestinal disease (29 patients), and rheumatoid arthritis (53 patients), burn injury (20 patients) and paraplegia (22 patients). Samples were studied from patients with a variety of cancers prior to treatment. They included 233 with lung cancer, 109 bladder 0 cancer, 64 colorectal cancer, and 75 from gastric cancer. Seventeen samples were from breast cancer prior to treatment, nine from recurrent breast cancer, and 25 from women who were tumour-free after treatment; 47 samples were tested prior to the treatment of chronic lymphocytic leukaemia (CLL); 25 samples prior to the treatment of Hodgkin's disease (HD) and 26 after treatment and 72 sera prior 
to the treatment of myelomatosis.

Urine samples were collected from patients with a variety of inflammatory conditions and known tubular proteinuria. Samples were stored at $-20^{\circ} \mathrm{C}$.

\section{PROTEIN MEASUREMENT}

SAA was measured by a modified single radial immunodiffusion (RID) method as developed by Dr J Whicher (personal communication 1982) based on the method of Mancini et al. ${ }^{18}$ In this method the plates were prepared normally with agarose ( $1 \% \mathrm{wt} / \mathrm{vol}$, HSA Litex) in barbitone buffer $\mathrm{pH} 8.6$ containing pulyethylene glycol (PEG, 5\% wt/vol) and goat antihuman SAA antiserum $\left(4 \mu \mathrm{l} / \mathrm{cm}^{2}\right.$; provided by Atlantic Antibodies, Scarborough, Maine, USA). After introducing the samples and standards into the wells, the plates were then incubated at $37^{\circ} \mathrm{C}$ for $36 \mathrm{~h}$ before extensive washing and pressing followed by staining with Coomassie blue $0.25 \% \mathrm{wt} / \mathrm{vol}$ in methanol/acetic acid/water $(5 / 1 / 5)$ and destaining with ethanol/acetic acid/water (3/1/ $6)$.

A standard SAA (prepared for the European Amyloid Research Society) was obtained from Dr J Whicher (Department of Chemical Pathology, Bristol Royal Infirmary, Bristol BS2 8HW).

Freezing and thawing (ten times) did not appear to significantly alter the concentrations of SAA in serum from normal subjects nor was there any difference in the values obtained in serum and plasma from the same donor, although serum gave clearer precipitin rings.

CRP and $\alpha_{1}$-acid glycoprotein (AGP) and IgG were measured by radial immunodiffusion (RID) incubated at room temperature for $48 \mathrm{~h}$ using antisera and standards obtained from Behringwerke AG (Marburg, Lahn, West Germany).

\section{IMMUNOELECTROPHORETIC METHODS}

SAA was measured using "rocket" immunoelectrophoresis ${ }^{19}$ at $37^{\circ} \mathrm{C}$ using antiserum $\left(3 \mu \mathrm{l} / \mathrm{cm}^{2}\right)$ and PEG $(5 \% \mathrm{wt} / \mathrm{vol})$ with agarose $(1 \% \mathrm{wt} / \mathrm{vol}$, HSA Litex) in barbitone buffer $(0.02 \mathrm{M}$; pH 8.6). Crossed immunoelectrophoresis ${ }^{20}$ was performed at $37^{\circ} \mathrm{C}$ or $15^{\circ} \mathrm{C}$ with PEG $(5 \% \mathrm{wt} / \mathrm{vol})$ and agarose $(1 \% \mathrm{wt} / \mathrm{vol}$ HSA Litex) in barbitone buffer $(0.02 \mathrm{M} ; \mathrm{pH} 8.6)$. Intermediate gels containing antiserum to HDL (Behringwerke AG, Marburg, Lahn, W Germany) were used in some experiments.

\section{Results}

SAA concentrations in serum samples as measured by RID were compared with those obtained using rocket immunoelectrophoresis. The correlation coefficient between results was very high $(r=0.98$; with a slope SAA (rocket) $=0.76 \times$ SAA $($ RID) + $41 \mathrm{mg} / \mathrm{l})$ although the concentrations were lower than those using RID at very high concentrations of SAA. The change in binding properties of SAA for $\mathrm{HDL}$ at $37^{\circ} \mathrm{C}$ was shown when for comparison the first dimension electrophoresis was run at $15^{\circ} \mathrm{C}$ and $37^{\circ} \mathrm{C}$. At $15^{\circ} \mathrm{C}$ the SAA coelectrophoresed with HDL ( $\alpha$-lipoprotein) as shown by an intermediate gel containing antiserum to $\mathrm{HDL}$ in crossed immunoelectrophoresis, and at $37^{\circ} \mathrm{C}$ the SAA electrophoresed at a much slower rate (in the $\beta 1-\beta 2$ region).

The concentrations of SAA in 35 women and 35 men blood donors were $18 \pm 13$ and $17 \pm 12 \mathrm{mg} / \mathrm{l}$ (mean $\pm \mathrm{SD}$ ) respectively. In 24 older men (follow-up of BPH) aged 56-83 yr the concentrations were $23 \pm 9 \mathrm{mg} / \mathrm{l}$ and they showed no significant increase with age. From the data an arbitrary upper limit of normal was taken as $60 \mathrm{mg} / \mathrm{l}$ although one normal serum examined had higher concentrations than the set limit. The arbitrary limit was calculated as the mean plus three standard deviations. This was the same criteria that established the upper limit of $10 \mathrm{mg} / 1$ for CRP for the same set of blood donors $(1 \cdot 8 \pm 2.4 \mathrm{mg} / \mathrm{l})$.

In seven patients the change in serum concentrations was followed over several days after elective cholecystectomy and the rates of change of SAA and CRP concentrations were found to correlate ( $r=0.52$; based on the logarithms of SAA and CRP to allow for their skewed distribution). An example of the rate of change in blood concentrations (Fig. 1) shows that the blood half-life for SAA

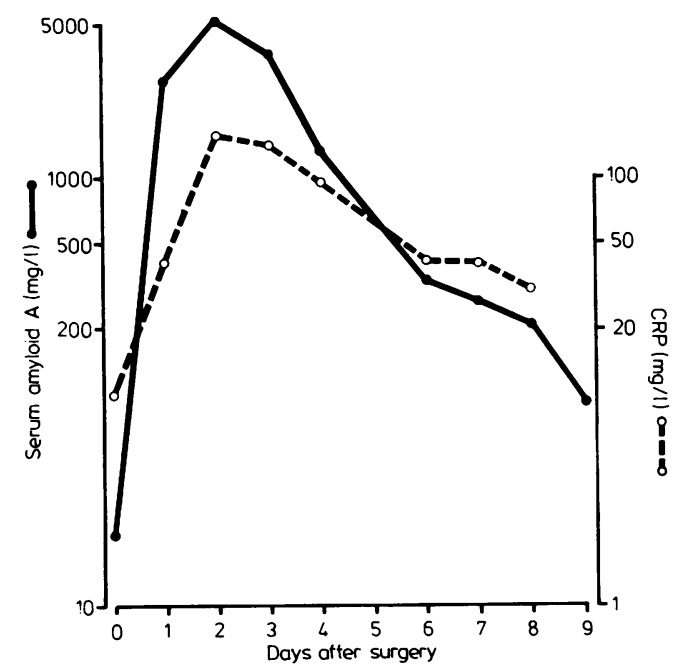

Fig. 1 Comparison of the response of SAA and CRP concentrations in a patient after an uncomplicated cholecystectomy. 
Table 1 Incidence of raised serum CRP concentrations in patients with inflammatory disease who have normal $(<60$ $\mathrm{mg} / \mathrm{l})$, moderately raised $(60-400 \mathrm{mg} / \mathrm{l})$, or greatly raised $S A A$ concentrations ( $>400 \mathrm{mg} / \mathrm{l})$.

\begin{tabular}{llcc}
\hline & \multicolumn{3}{l}{$S A A(m g / l)$} \\
\cline { 2 - 4 } & $<60$ & $60-400$ & $>400$ \\
\hline Liver disease & & & \\
PBC & $0 / 16$ & $2 / 15$ & $6 / 8$ \\
CAH & $0 / 22$ & $0 / 9$ & $3 / 3$ \\
AC & $0 / 9$ & $3 / 4$ & $0 / 0$ \\
Rheumatoid arthritis & $3 / 10$ & $12 / 21$ & $21 / 22$ \\
Burn injury & $0 / 1$ & $0 / 1$ & $18 / 18$ \\
Paraplegia & $1 / 11$ & $2 / 5$ & $6 / 6$ \\
Inflammatory G-I disease & $0 / 15$ & $4 / 9$ & $5 / 5$ \\
\hline
\end{tabular}

$(1 \cdot 1 \pm 0 \cdot 3$ days) was normally shorter than that for CRP $(2 \cdot 2 \pm 0 \cdot 9$ days $)$.

Low concentrations of SAA $(50 \mathrm{mg} / \mathrm{l})$ could be detected in the urine from 11 out of a total of 39 patients with a variety of both chronic and acute renal diseases. SAA occurred most commonly in patients with chronic or acute pyelonephritis ( 7 of 11). Those patients with detectable SAA were all within the group of 28 patients with urinary IgG concentrations $>90 \mathrm{mg} / \mathrm{l}$, whilst SAA was not found in 17 patients with lower IgG concentrations. In 20 patients with burns, 19 of whom had raised acute phase reactants in the blood (Table 1), only four had detectable concentrations in the urine (in two it was 140 and $460 \mathrm{mg} / \mathrm{l}$ ). SAA was not detectable in the urine of 20 patients with paraplegia, the majority of whom had chronic urinary infections of varying severity.

\section{SERUM CONCENTRATIONS IN NON-MALIGNANT DISEASE}

Serum concentrations of SAA and CRP were measured in chronic active hepatitis $(\mathrm{CAH})$, primary biliary cirrhosis (PBC), and alcoholic cirrhosis (AC) and benign inflammatory gastrointestinal diseases, as well as rheumatoid arthritis. It was found that in some patients the concentrations of SAA were higher than the designated upper limit of normal whilst the CRP concentrations were not raised. These diseases were compared to the concentrations in patients with burn injury in whom there was usually a pronounced acute phase reaction and to patients with paraplegia of many years duration who had chronic inflammation due to pressure sores or other causes. The association of these two indices of the inflammatory response (SAA and CRP) is shown in Table 1.

\section{SERUM CONCENTRATIONS IN MALIGNANT DISEASE}

SAA was measured in lymphoma, myelomatosis, and chronic lymphocytic leukaemia (CLL). There

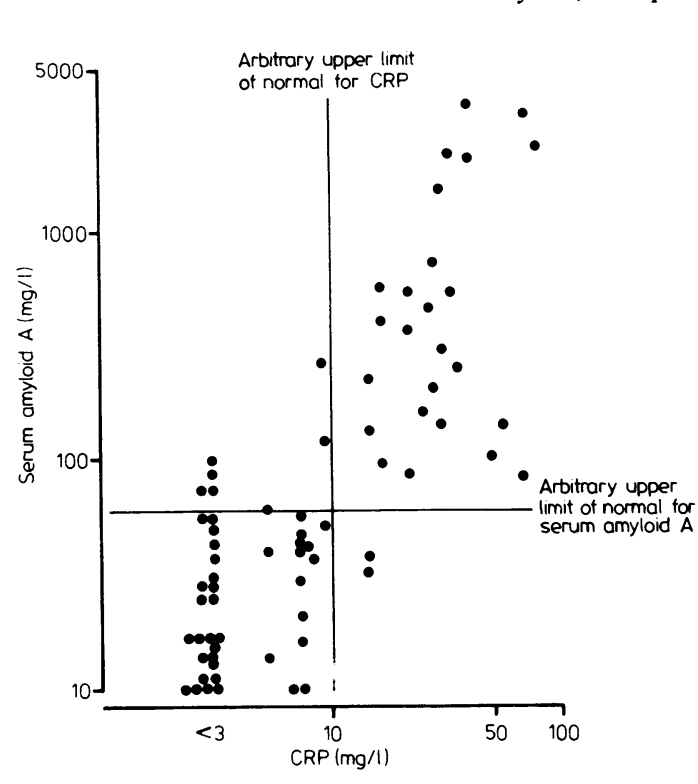

Fig. 2 Distribution of SAA and CRP concentrations in patients with myelomatosis.

was a good correlation between CRP and SAA in all diseases examined, the results for myelomatosis in Fig. $2(r=0.70)$ are typical of these findings. The level of serum SAA was also found to correlate well with serum AGP in patients with myelomatosis $\mathbb{Q}$ $(\mathrm{r}=0.76$, for AGP $v \operatorname{logSAA})$. The pretreatment serum samples from patients with stage I and II Hodgkin's disease (HD) showed a larger number of patients with raised concentrations of both SAA (8릉 out of 13) and CRP (5 out of 13) than the corresponding samples for the same stage in remission (2웅 out of 13 with raised SAA and 0 out of 13 with raised CRP). The pretreatment samples from $47 \stackrel{3}{3}$ patients with CLL (stage 0,29 ; stage I, 6 ; stage II, 8 ; $\stackrel{\bigcirc}{\circ}$ stage III \& IV, 6) had a low frequency of raised $₹$ acute phase reactants (8 with raised SAA, and 6 윽 with a raised CRP). Pretreatment HD samples of $>$ stage III and IV had a high proportion with raised SAA (8 out of 11) and raised CRP (8 out of 11).

In carcinomas there was again a high correlation between the levels of $\log C R P$ and $\operatorname{logSAA} \sim \widetilde{\sim}$ $(r=0.77)$. Comparison of the number of patients with raised or normal concentrations of SAA reveals 0 that about $21 \%$ of the 579 patients with normalo CRP concentrations had a raised SAA, although this was higher in some types of cancer than others. This $\stackrel{?}{+}$ dissociation is not as great as that found in some $\square$ non-malignant diseases such as rheumatoid arthritis $\frac{\vec{P}}{\mathrm{D}}$

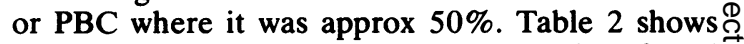
that a greatly increased SAA concentration, found $\stackrel{\mathbb{Q}}{\Omega}$ in 172 cancer patients, was with only two exceptions accompanied by a raised CRP concentration. How- 
Table 2 Incidence of raised serum CRP concentrations in patients with malignant disease who have normal, moderately raised or greatly raised $S A A$ concentrations.

\begin{tabular}{llll}
\hline & \multicolumn{3}{l}{$S A A(m g / l)$} \\
\cline { 2 - 4 } & $<60$ & $60-400$ & $>400$ \\
\hline Lung cancer & $4 / 56$ & $53 / 77$ & $99 / 100$ \\
Bladder cancer & $4 / 51$ & $11 / 27$ & $31 / 31$ \\
Colorectal cancer & $0 / 22$ & $10 / 26$ & $16 / 16$ \\
Gastric cancer & $1 / 26$ & $7 / 24$ & $24 / 25$ \\
\hline
\end{tabular}

ever, there was a group of patients (154) with moderately raised SAA, of whom $47 \%$ have CRP concentrations within the normal range.

The concentrations of SAA in various types of solid tumours (lung, bladder, stomach, and colorectal) were compared with regard to stage. It can be seen from Fig. 3 that the more advanced stages had a higher proportion of raised SAA concentrations (normally accompanied with a raised CRP). The SAA concentrations of even the earliest and most advanced stages were shown to overlap. This overlap was present in all the cancers examined in this series. The increase in median SAA concentrations of different stage III of stomach and lung cancer and HD is shown in Table 3 . Primary breast cancer stages I-III were found to be a poor stimulus for the acute proteins and SAA concentrations were not raised in 17 pretreatment patients or 24 patients who were subsequently tumour-free after surgery,

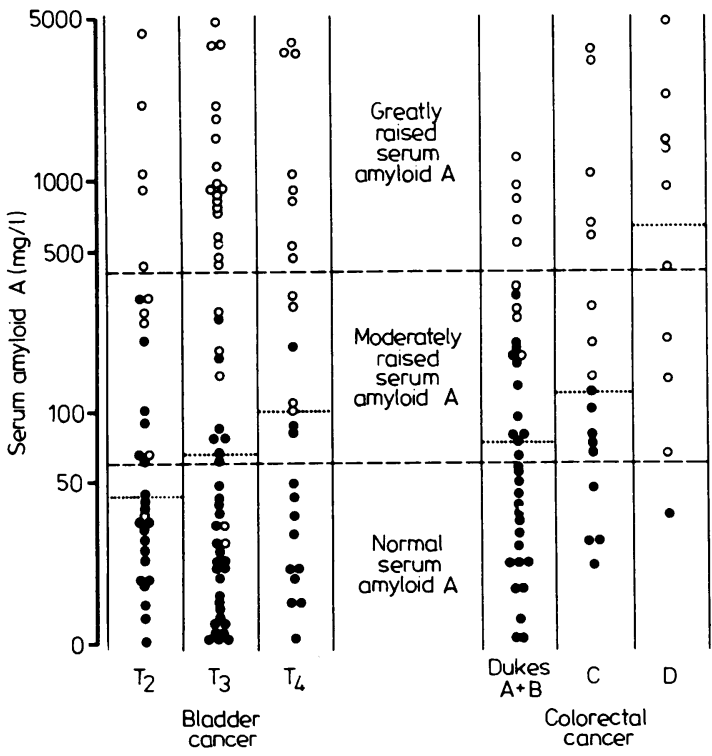

Fig. 3 A comparison of serum amyloid $A$ concentrations in solid malignancies at different stages $(O=$ raised $C R P$ $>10 \mathrm{mg} / \mathrm{l} ; \mathrm{O}=$ normal $C R P<10 \mathrm{mg} / \mathrm{l})$. The transverse dotted line represents the mean $S A A$ level for each of the groups of patients with cancer at different stages.
Table 3 Median concentrations of SAA in serum from patients at different stages of malignant disease.

\begin{tabular}{|c|c|c|c|c|}
\hline & \multicolumn{4}{|c|}{ SAA (mgll) (No of patients) } \\
\hline & Stage I & II & III & $I V$ \\
\hline Lung cancer & $\underbrace{88(48)}$ & $130(32)$ & $275(114$ & $230(18)$ \\
\hline Gastric cancer & \multicolumn{2}{|c|}{$140(13)$} & $62(28)$ & $465(34)$ \\
\hline $\begin{array}{l}\text { Pretreatment } \\
\text { Hodgkin's disease }\end{array}$ & \multicolumn{2}{|c|}{$25(14)$} & \multicolumn{2}{|c|}{$560(11)$} \\
\hline $\begin{array}{l}\text { Posttreatment } \\
\text { Hodgkin's disease }\end{array}$ & \multicolumn{2}{|c|}{$19(13)$} & \multicolumn{2}{|c|}{$42(13)$} \\
\hline
\end{tabular}

but SAA concentrations were moderately raised in three out of six patients with recurrences.

Metastatic colorectal (Dukes "D"; Fig. 3) had a much higher median SAA level than non-metastatic cancer (Duke's A+B). Nevertheless, there was still considerable overlap between the groups. Similarly 25 patients with metastatic gastric cancer had a median concentration of $480 \mathrm{mg} / \mathrm{l}$ whilst 50 nonmetastatic patients had a median SAA concentration of $90 \mathrm{mg} / \mathrm{l}$. However the range of SAA concentrations in each group was similar (with metastases $22-5500 \mathrm{mg} / 1$; without metastases $12-4600 \mathrm{mg} / \mathrm{l}$ ). Many of the stage IV gastric cancer patients had liver metastases and not all of them had significantly raised concentrations of SAA. Patients with nonmetastatic prostatic cancer had a median SAA concentration of $25 \mathrm{mg} / \mathrm{l}$ whilst 19 patients with metastatic disease had only a slightly higher median SAA concentration $(38 \mathrm{mg} / \mathrm{l})$.

\section{Discussion}

Concentrations of SAA were found to correlate well with CRP in all the diseases examined and also in serial samples. This agrees well with previous data on groups of patients and also on serial SAA concentrations. $^{8913}$ The serial measurements either used an injection of etiocholanolone (a naturally occurring steroid metabolite which has the property of being a non-antigenic human pyrogen) to produce an acute phase response ${ }^{9}$ or were on patients after elective surgery. ${ }^{8}$ In experiments on serial measurements of SAA, in this study in patients after cholecystectomy, the time required for SAA concentrations to halve their original value (mean $1 \cdot 1$ days) was shorter than that of CRP (mean $2 \cdot 2$ days). The half-life of SAA has been measured at 40-60 $\mathrm{min}^{21}$ in normal mice injected with ${ }^{125}$ I-labelled material which was considerably shorter than the halflife of labelled apo A-1 or other apolipoproteins. Thus, the slower blood half-life observed after wounding is presumably due to the combined effects of the decreased rates of synthesis as the inflammatory response waned and possibly a fixed rate of 
clearance. This is in agreement with the suggestion that the putative inducer of SAA synthesis in liver, interleukin 1, is required for continued SAA synthesis. It may be that CRP like SAA is induced by interleukin $1 .^{22}$ The dissociation of the concentrations of these two acute phase proteins, in some patients, may be due to differences in their rates of clearance from the blood. The fact that SAA has been shown to have a much shorter half-life in mice than other apolipoproteins is interesting in view of the reduction in binding or change in structure that appears to occur between HDL and SAA at higher temperatures, and it may be possible that SAA is only bound firmly to HDL at lower temperatures (eg $15^{\circ} \mathrm{C}$ ). Concentrations of SAA increased up to 200 fold during the acute phase reaction and can reach approximately $5 \mathrm{~g} / \mathrm{l}$. The measurement was based on the standard of the European Amyloid Research Society and cannot be compared directly with values obtained in radioimmunoassays (normal levels by radioimmunoassay obtained by other researchers are $\left.<220 \mathrm{ng} / \mathrm{ml} ;{ }^{10}\right)$. It was likely that SAA concentrations were a more sensitive indicator of inflammation than CRP because of the more rapid increase in SAA and the greater increase in concentrations obtained after the same stimulus. It was found that the group of elderly men (BPH recalls) did not have an increased SAA despite previous reports that the elderly subjects can exhibit raised SAA. ${ }^{2316}$ Our result agrees with the more recent observations on large numbers of elderly people in which no increase in SAA with age was observed. ${ }^{17}$ The reason for the different results obtained by other investigators ${ }^{2316}$ may be due to differences in the specificities of the immunoassays employed. However, the finding that there was no increase makes it logical to compare patients with diseases that have a different age distribution.

The finding that SAA could be detected in the urine of patients with pyelonephritis is probably consistent with an increased high-molecular-weight proteinuria and the acute inflammatory response in the serum of patients with pyelonephritis. ${ }^{23}$ Although most patients with burn injury did not have detectable concentrations of SAA in their urine there were two exceptions with particularly high concentrations which cannot be explained by an associated glomerular defect. It was possible that the protein was a fragment of SAA reacting with the antisera.

The distribution of patients according to whether SAA and CRP were raised or normal was similar in all types of cancer examined, although lung cancer displayed the highest proportion of patients with raised SAA and normal CRP concentrations. Generally the percentage with raised SAA and normal
CRP was approx $10-30 \%$ and the converse (normal $\stackrel{0}{\circ}$ SAA and raised CRP) was rare. Amongst the nonmalignant diseases, however, $\mathrm{PBC}$ and rheumatoid $\overrightarrow{\mathrm{F}}$ arthritis and to a lesser extent $\mathrm{CAH}$ showed a much higher proportion of patients with raised SAA and $\frac{C}{O}$ normal CRP. Thus despite reports to the contrary ${ }^{16} \frac{\bar{\omega}}{\bar{\omega}}$ it would appear that chronic liver disease can cause $\overparen{D}$ an increase in SAA although concentrations attained were not as high as those in some acute ${ }^{\infty}$ inflammatory states and CRP was not often raised. $\vec{O}$ It may be that the increased SAA found in patients $\overrightarrow{-}$ with PBC may be due to the often associated sys- $\omega$ temic disorders. It has been suggested that the $\widehat{\circ}$ occurrence of amyloid deposits correlated with the incidence of very high SAA concentrations in cer- $\%$ tain diseases although this is not the only require- $v$ ment for the deposition of amyloid. ${ }^{14}$

In the haematological malignancies, found to give CRP and SAA concentrations in the? normal range, a finding in agreement with previous $\vec{C}$ reports ${ }^{11}$ although the patients examined were gen- $-\frac{\varrho}{<}$ erally of an early stage.

Our results do not match the clear separation $\infty$ between SAA concentrations of disseminated cancer and local or regional cancer that were reported previously. ${ }^{11}$ The reason for this is not clear. The occurrence of infection in some malig-o nancies can cause an increase in CRP; ${ }^{22}$ however, infection was present in very few of the patients in 0 this study, mainly it was limited to those patients $\overrightarrow{\vec{O}}$ with CLL and myelomatosis who presented with 3 raised acute phase reactant proteins. In the majority? of cancer patients with an acute phase response; this? is attributable to the reaction to products of tissue destruction. ${ }^{24}$

In all the diseases we studied SAA appeared to be $\frac{\overline{0}}{3}$ more sensitive an index of an acute phase response than CRP independent of the cause of the inflammatory reaction. Furthermore the claims that high concentrations of SAA are associated with the presence of distant metastases are not substantiated $\frac{D}{0}$ The introduction of an improved assay may facilitate SAA measurement but is unlikely to change the $\tilde{N}$ general picture in neoplastic disease.

We would like to thank Atlantic Antibodies for ${ }^{\mathrm{W}}$ kindly providing the antiserum to SAA; and the surgeons and physicians of the United Leeds Hospi-O든 tals for permission to investigate their patients, and Mrs Malathi Raghava for preparing the manuscript.+?

\section{References}

${ }^{1}$ Levin J, Pras M, Franklin EC. Immunologic studies of the major non-immunoglobulin amyloid protein of amyloid. $J$ Exp Med< 1973;138:373-80. 
${ }^{2}$ Husby G, Natvig JB. A serum component related to nonimmunoglobulin amyloid protein AS, a possible precursor of the fibrils. J Clin Invest 1974;53:1054-61.

${ }^{3}$ Benson MD, Skinner M, Lian J, Cohen AS. "A" protein of amyloidosis. Isolation of a cross-reacting component from serum by affinity chromatography. Arthritis Rheum 1975;18:318-22.

4 Linke RP, Sipe JD, Pollock PS, Ignaczak TF, Glenner GG. Isolation of a low molecular-weight serum component antigenically related to an amyloid fibril protein of unknown origin. Proc Natl Acad Sci USA 1975;72:1473-6.

5 Benditt EP, Eriksen N. Amyloid protein SAA is associated with high density lipoprotein from human serum Proc Natl Acad Sci USA 1977;74:4025-8.

- Skogen B, Borreson AL, Natvig JB, Berg K, Michaelsen TE. High density lipoprotein as carrier for amyloid-related protein SAA in rabbit serum. Scand J Immunol 1979;10:39-45.

' Benson MD, Kleiner E. Synthesis and secretion of serum amyloid protein A (SAA) by hepatocytes in mice treated with casein. J Immunol 1980;124:495-9.

s Gorevic PD, Rosenthal CJ, Franklin EC. Amyloid related serum component (SAA) studies in acute infections, medullary thyroid carcinoma and post surgery. Clin Immunol Immunopathol 1976;6:83-93.

9 McAdam KPWJ, Elin RJ, Sipe JD, Wolff SM. Changes in human serum amyloid $\mathbf{A}$ and $\mathrm{C}$-reactive protein after etiocholanolone-induced inflammation. $J$ Clin Invest 1978;61:390-4.

${ }^{10}$ Rosenthal CJ, Sullivan LM. Serum amyloid A to monitor cancer dissemination. Ann Intern Med 1979;91:383-90.

"Rosenthal CJ, Noguera C, Platica O, Sullivan L. Serum amyloid A: Monitor of cancer dissemination. In: Glenner GC, Costa PP, Falco de Freitas, eds. Amyloid and amyloidosis Amsterdam: Excerpta Medica, 1980;43-9.

${ }^{12}$ Benson MD, Cohen AS. Serum amyloid A protein in amyloidosis, rheumatic and neoplastic diseases. Arthritis Rheum 1979;22:36-42.

${ }^{13}$ Maury CPJ, Teppo AM, Wegelius O. Relationships between urinary sialylated saccharides, serum amyloid $A$ and $C$-reactive protein in rheumatoid arthritis and systemic lupus erythematosus. Ann Rheum Dis 1982;412:268-71.

14 deBeer FC, Mallya RK, Fagan EA, Lanham JG, Hughes GRV, Pepys MB. Serum amyloid A protein concentrations in inflammatory diseases and its relationship to the incidence of reactive systemic amyloidosis. Lancet 1982;ii:231.

is Husby G, Lindstrom FD, Natvig JB, Dahlstrom V. Occurrence of amyloid-related serum proteins in patients with benign monoclonal gammopathy. Scand J Immunol 1977;6:659-63.

${ }^{16}$ Rosenthal CJ, Franklin EC. Variation with age and disease of an amyloid A protein related serum component. J Clin Invest 1975;55:746-53.

${ }^{17}$ Hijmans W, Sipe JD. Levels of the serum amyloid A protein (SAA) in normal persons of different age groups. Clin Exp Immunol 1979;35:96-100.

18 Mancini G, Carbonara AU, Heremans JF. Immunochemical quantitation of antigens by single radial immunodiffusion. Immunochemistry 1965;2:235-54.

${ }^{19}$ Laurell CB. Quantitative estimation of proteins by electrophoresis in agarose gel containing antibodies. Anal Biochem 1966;15:45-52.

${ }^{20}$ Weeke B. Crossed immunoelectrophoresis. Scand J Immunol 1973;2:suppl 1;47-56.

${ }^{21}$ Benditt EP, Eriksen N, Hoffman JS. Origin of protein AA. In: Glenner GC, Costa PP, Falco de Freitas, eds. Amyloid and Amyloidosis Amsterdam: Excerpta Medica, 1980:397-405.

${ }^{22}$ Kushner I, Ribich WN, Blair JB. Control of the acute phase response. C-reactive protein synthesis by isolated perfused rabbit liver. J Lab Clin Med 1980;96:1037-45.

${ }^{23}$ Morley JJ, Kushner I. Serum C-reactive protein levels in disease. Ann NY Acad Sci 1982;389:406-18.

${ }^{24}$ Cooper EH, Stone J. Acute phase reactant proteins in cancer. In: Klein G, Weinhouse S, eds. Advances in Cancer Research New York: Academic Press, 1979;30:1-44.

Requests for reprints to: Professor EH Cooper, The Unit for Cancer Research, School of Medicine, Leeds LS2 9NL, England. 